\title{
Demystifying media neutrality
}

Received (in revised form): 5th June, 2003

\section{Peter Mitchell}

is managing director of WWAV Rapp Collins Media, and has worked in the media industry since starting with United Newspapers some 13 years ago. He joined WWAV RC Media from Optimedia in 1998 and was responsible for integrating all the media business across the agency. He was made managing director in 2000. WWAV RC Media are specialists in direct marketing and part of the WWAV RC Media Group.

\begin{abstract}
Media neutrality is by no means new to the marketing industry. The key behind the drive for a neutral approach has been clients' desire for accountability. As budgets tighten marketing departments are being told to account for the money they spend and to prove ROI. It is this request for proof on investment that has driven many clients to consider the more measurable media. This paper takes the mystery out of methodologies behind the integrated approach and looks at how clients and agencies should be working together for the best of the brand, not just the award-winning television campaign.
\end{abstract}

\section{INTRODUCTION}

Many organisations are being told that media neutrality is an important prerequisite for campaign planning that fairly balances the mix of media channels available to advertisers today. No self-respecting agency would admit that it was not central to their core offering. The concept is hardly new, however, and has been around in various guises for the past decades.

It is, in fact, clients that have led the change by not only demanding more accountability for their advertising spend but also by launching new brands from old establishments. Both HSBC with First Direct and Prudential with Egg forced agencies to come up with a new game plan. Both of these new financial brands are internet based and as offshoots have no barriers or old-established methodologies to hold them back. As other companies began to change their structure and throw out their traditional approach to business acquisition and media, their new open attitude began to meet with outstanding successes. It is this change in companies' ways of thinking about media platforms that has forced agencies to pay more than lip service to the idea of neutrality.

So born mainly from the need of above the line agencies to raise their gambit in the face of shrinking budgets and increasing pressures to justify media spend, neutrality has become the new tool with which to charm the client. Although good in theory, the problem is that while above the line agencies may have the marketing expertise to develop the media neutral proposition, they do not follow through with accountability and delivery experience. As a result, the deliverance of media neutrality has been patchy, at best, from most of those claiming to be experts.

Media neutrality should not be perceived as an emerging fashion that requires new wave thinking and a sharp learning curve; it is the natural evolution of communications planning. It relies on a strong, inclusive bond where clients 


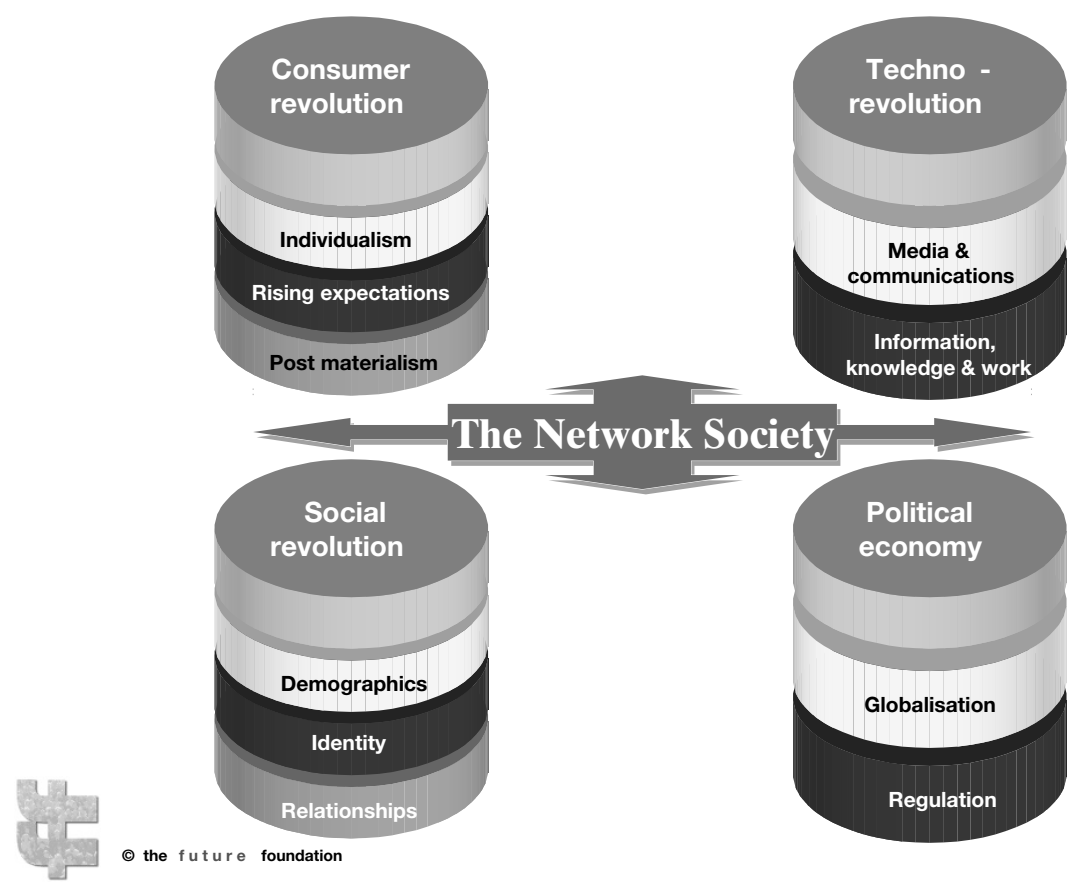

Figure 1 Four interlocking revolutions

and media planners work in partnership to devise customer-focused communication strategies and meet the objectives of corporate business plans.

Few media agencies these days want to be labelled as mere space brokers. Clients expect and deserve a broad spread of channel understanding from their media agents and media and audience fragmentation means solutions must be offered across a range of media. There is no future for any agency that is single-disciplined; it is essential to develop a plan that is appropriate for the brand and relevant to its customers, and then run it across several media. If the strategy is sound it will work.

\section{MEDIA PLANNING}

'Our agency takes a media neutral approach to communications planning ...' tends to be the opening strategy in most credentials pitches. This may be the right sentiment, but it needs to be founded firmly in strategic planning and processes. While every agency wants to claim expertise across the board, this can be a dangerous approach. Agencies should be able to demonstrate an understanding of their client's brand strategy and how to integrate that into a broader media plan. Making ambitious promises and failing to deliver on them is a sure way to enrage clients and send them running into the arms of a rival.

For WWAV Rapp Collins Media, media planning is about understanding the breadth and depth of opportunity that the entire media context delivers and applying that knowledge to deliver its clients' communications through the channels that most effectively meet their business targets. By definition the planning process requires the consideration of, and expertise in all media channels, including door-to-door, television, telephone and cold mail. The outstanding question of integration is heightened by the plethora of different 


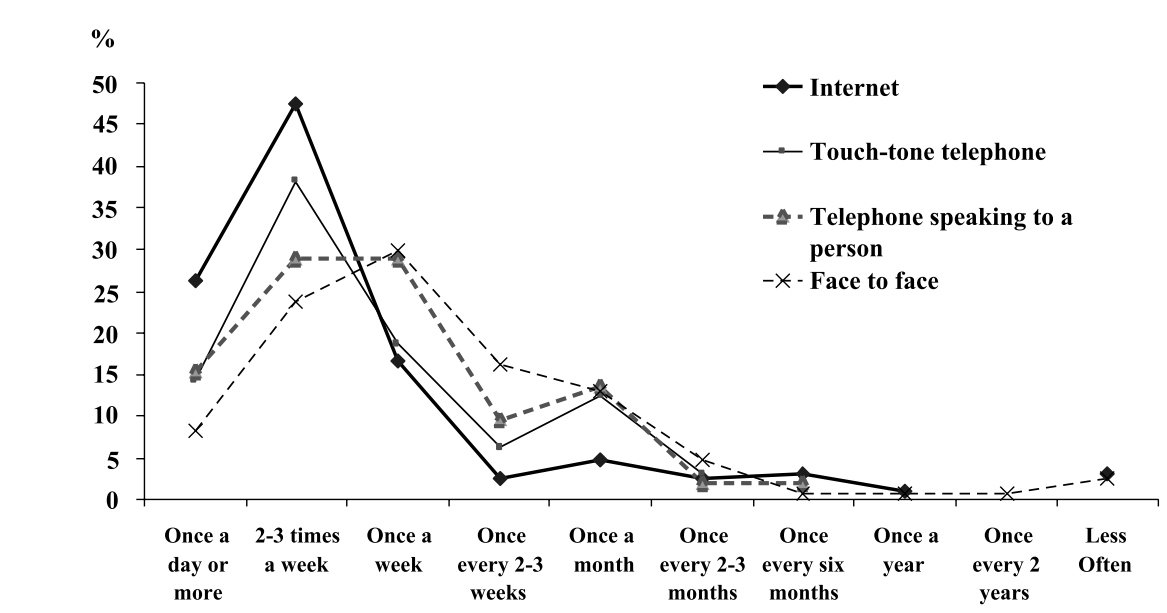

Source: Self-service Society Consortium/The Future Foundation

Base: 446 respondents

Figure 2 Internet customers have the most contact with their bank

channels that are available to and used by customers. With the continuing evolution and hybridisation of existing media channels it seems more and more that the only realistic point of integration is likely to be the customer, especially in the light of the growing tendency for the public to 'manage' its own interfaces with suppliers of products and services.

The technological revolution is just one of four which interlock, making up a networked society ${ }^{1}$ - the driving factor behind the search for greater individuality and self-expression.

As research has confirmed over the years, ${ }^{1}$ some people prefer the intimacy and personal touch of voice communication over the telephone, others like the control and efficiency of e-mail, some love the constant contactability of mobiles and text messaging, while many still favour the ability to be exposed to all content, while selecting out their areas of interest. The latter will remain an important function of newspapers and television. As a result, brands and advertisers are faced continually with a delicate balancing act, at the centre of which is the consumer.
Companies must remember that it is not only creating the contact opportunity that is important but managing each medium effectively as they are brought into the mix.

\section{PLANNING EQUALS CONSUMER INSIGHT}

From a planning perspective, the consumer is key to the process and any integration has to centre on them. Media neutral strategy planning requires open minded thinking: thinking outside any single media channel and any single discipline. It means thinking like a consumer of the product or service and building the rulebook from this point.

Research from the Future Foundation ${ }^{1}$ shows that when simply looking at the technological advances in media there is a constant crossing over and blurring of media. As the research says 'The winners in our advanced consumer society will be those that confer clear benefits to the consumer'. When the more traditional media platforms are included the blending of the media becomes ever more important. 


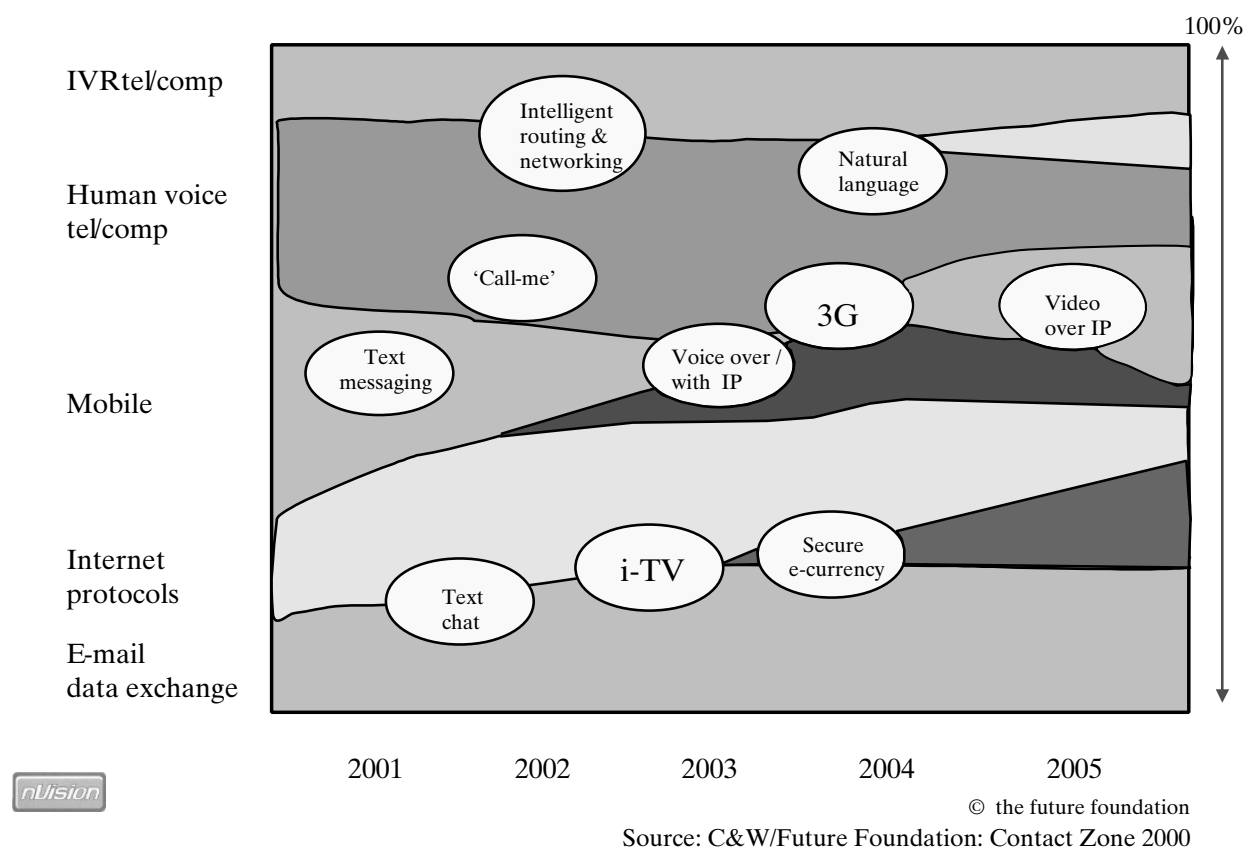

Figure 3 Planning in the context of evolving platforms

One of the most noticeable developments in the relationship between supplier and consumer is that of customer centricity. In a world of ever-increasing choice, the need for clients to protect their customer base is paramount; a customer-focused integrated communications strategy is the key to this. This will make the difference between a successful and an unsuccessful brand, as has been demonstrated by brands like Orange, Egg, BMW and Vodafone. Brand values have to be communicated to the consumer at every 'touch-point' to acquire and retain valuable customers; from a television campaign down to the sales force.

Real consumer insight has to be positioned at the core of the integrated planning process and the planner must gather a complete picture of the client's stakeholders, who they are, their mindset, media consumption patterns and relationship with the business - are they 'life-time' consumers or have they purchased once, are they high-value or low-value customers. This requires lifting the bonnet of the database, market evaluation and often audience segmentation.

Ultimately, the solution delivered will be very specific, tailored to each client and not every media channel or communication discipline will be used, just the ones that are most effective. Each, however, needs to be considered initially if the best one is to be selected. At the same time, agencies need to understand how all the media channels fit together, including direct and PR. Direct marketing is in long-term growth, but integration with above the line agencies tends to be a rarity. PR campaigns frequently operate in total isolation from paid-for media communications. While media neutral planning is agreed as the optimum approach, putting it into practice is proving more challenging. Some agencies already have systems that attempt to 
optimise coverage in this way. The solution has to be a closer working partnership between agencies and clients and the earlier in the strategy development that agencies sit down with client brand custodians and marketing executives, the more closely they can plan a coordinated media campaign. When considering the right media channel for a communication, the media planner should be thinking "What is the audience here and how can we reach them better?'

\section{CLEAR OBJECTIVES}

Once the consumer insight has been addressed, the task is to map the media journey of each target group and to channel the plan to meet client objectives. What is the campaign hoping to achieve? Is it brand awareness or sales? The challenge is then how to balance the communications delivery to meet targets as well as integrating the plans with disciplines that the planner may be less familiar with: for example, field sales, inserts or PR. Traditional media companies that are steeped in brand experience will need to broaden their repertoire to compete. Only the more forward thinking among media groups can genuinely provide a range of dedicated specialists in all fields. Then the partnership with the client comes into play. By definition, clients who are thinking strategically should welcome the role they have to play in the planning process.

\section{Synergy: in media planning, creativity and the client's business}

The key is to ensure that the message and experience of the brand remain consistent at all points of contact with the consumer in the extending interface. Media planning and creativity must have the same objectives and be accountable to the brand and to the results of the campaign. Not only must there be brand synergy throughout the creative but the organisation should also be looking for creative use of media channels. Once the organisation is satisfied with its brand's meaning and its place in customers' lives, there is a base for building the brand irrespective of the medium, the channel or direction of the communication. Neutrality lies with the content not with the medium - meaning that the content and purpose must be communicable, irrespective of the carrier.

One of the best illustrations of this approach is Kit Kat, ${ }^{2}$ for 15 years the UK's leading confectionary brand. Until only a few years ago, Kit Kat was a classic television-led FMCG brand, on air for about a third of the year with four bursts - once a quarter. Kit Kat had a great strategic position for a chocolate brand and one of the UK's most famous selling lines - 'Have a break, have a Kit Kat'.

Now Kit Kat is a multimedia brand — part of the fabric of daily life. Its presence is everywhere and is spread across television, posters, press, radio and the internet. A combination of short time-length television and new work for radio, press and outdoor enabled Nestle to build this great brand quickly. By taking the famous 'Have a break' positioning and extending the message creatively the creative work was media neutral but the marketing planning was media integrated.

It is not only agencies that need synergy; there must be synergy of intention across the client's business. This is essential to media communication and promotion of the brand. Budgets cannot be in silos; if they are, a vicious and negative circle will develop of marketing leading operations and operations leading marketing; otherwise the customer will 


\section{The Past}

TV

- 4 bursts

- 16 weeks

-2 creative executions

\section{Posters}

-2 bursts

-1 execution

Figure 4 Former Kit Kat advertising

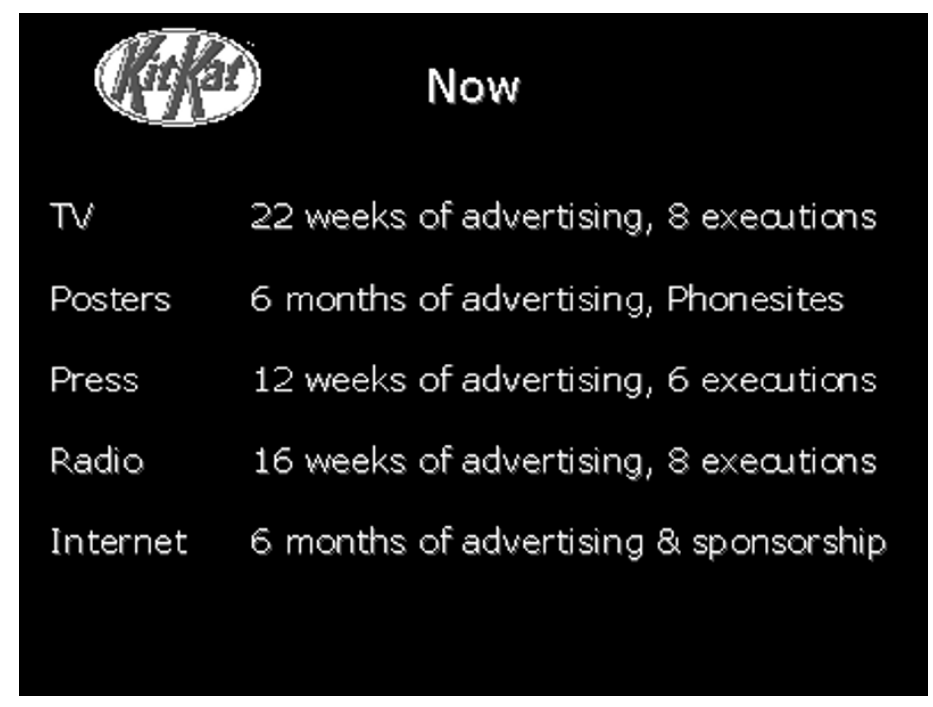

Figure 5 Kit Kat advertising now

be lost and the brand experience weakened. Clients must have a good business plan in place and the business to back up the more direct response-driven media. If they do not, the strategy will implode and failure will result.

Media neutral thinking also requires the planner to evaluate media selection according to better brand value, not to price value. If the big budgets are not there any more, planners should devise different solutions.

\section{UNDERSTANDING THE DATA TOOL BOX}

It is not easy to manage a media neutral, integrated campaign. The complexities involved mean that high levels of quality control are needed to ensure accuracy of delivery.

WWAV RC Media Group has developed a bespoke campaign management tool that provides eight stages to campaign management and ensures the best possible standards at 
Table 1: Available media

\begin{tabular}{llllllllll}
\hline & DRTV & $\begin{array}{l}\text { Door to } \\
\text { door }\end{array}$ & $\begin{array}{l}\text { Cold } \\
\text { list }\end{array}$ & Directories & Insert & Radio & $\begin{array}{l}\text { Bus } \\
\text { sides }\end{array}$ & $\begin{array}{l}\text { Six } \\
\text { sheet }\end{array}$ & $\begin{array}{l}\text { Phone } \\
\text { boxes }\end{array}$ \\
\hline $\begin{array}{l}\text { Control regions } \\
\text { Hot house } \\
\text { regions }\end{array}$ & $\sqrt{ }$ & $\checkmark$ & $\checkmark$ & $\checkmark$ & $\checkmark$ & $\checkmark$ & & & \\
\hline
\end{tabular}

every stage of the campaign from brief to final consumer response. These are:

- Market context

- Campaign requirements

- Consumer insight

- The strategy

- Implementational planning

- Buying

- Measurement and reporting

- Learning

Clients have found this to be an effective way of focusing on creative approaches that integrate with effective and innovative communication solutions.

The principle of measurement and evaluation is another key part to the delivery of media neutral campaigns. The direct response angle and the mantra at the media group is: 'if you can't measure it, we shouldn't be doing it'; it helps focus the mind and enables the effective evaluation of all direct campaigns.

With integrated media campaigns, evaluation is less straightforward. One solution is to use econometric modelling which combines clients' results from direct channels with assessment of external influences such as market trend data, brand awareness tracking and outside uncontrollable factors, such as the weather or world events, that could have an impact on campaign effectiveness.

The development of tailored econometric models provides a method to aid the understanding of the media-multiplier effect from the integration of communication channels. It also makes possible the evaluation of a host of other factors including brand contribution and the impact of pricing and consumer attitudes on business targets.

Take, for example, the car insurance industry; it is one of the most competitive in the financial sector and has, therefore, traditionally been led by price. By determining how sales are related to a number of economic and demographic variables through the use of econometric modelling, however, WWAV Rapp Collins Media's client, AXA, ${ }^{3}$ was able not only to build sales and brand awareness but was also in a position to measure directly which media channels worked effectively.

The insurer had had a silo approach to planning with no liaison between call centres and media activity and poor reporting systems; not even customer communications were included in the media planning. Working closely with AXA, the agency used econometric models to test media in four regional areas in the UK; two sites tested media across the board while the control area tested only the media normally used. The model allowed all available media to be examined against Axa's customer segments. This in turn enabled the selection of media.

The model delivered solutions from two directions:

- Starting with a medium the model identified postcode sectors where this medium delivers best coverage

- From a postcode sector the model showed 


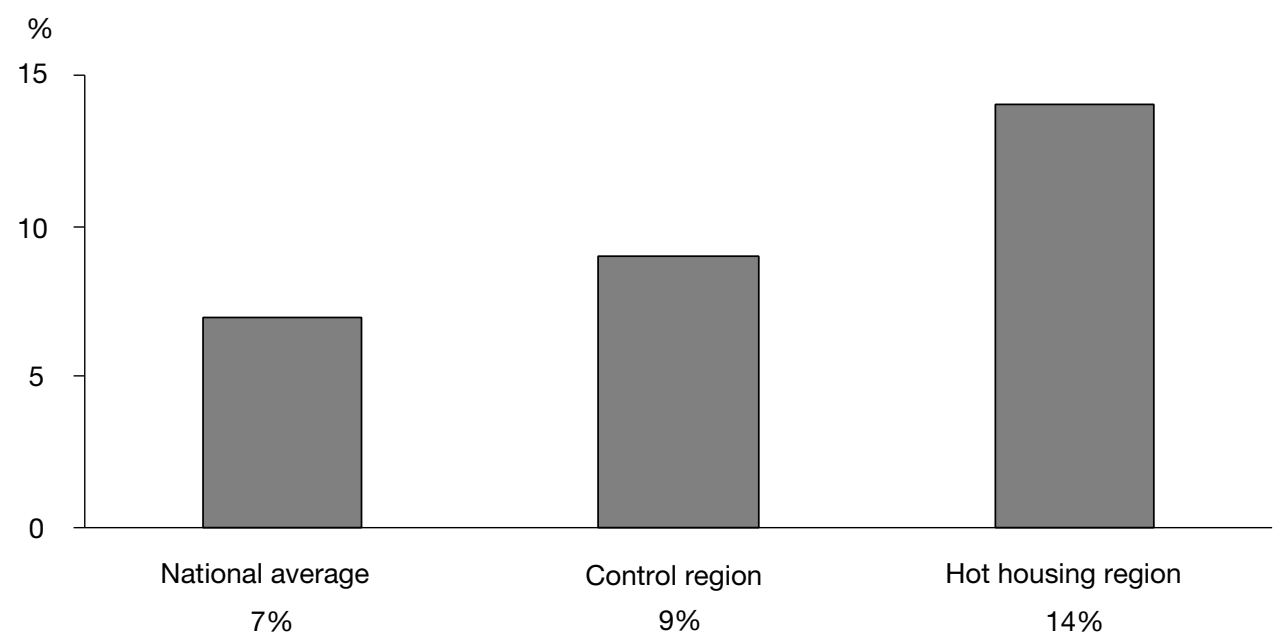

Figure 6 Increase in quotes within 'hot house' and control areas

best fit of media to reach each postcode sector.

The output from the segmentation modelling allowed the agency to develop and produce a media bible which looked at all potential media available within each of the areas selected.

Because of the dual-purpose nature of the campaign (ie building awareness and generating cost-effective response) two measurement criteria were applied: soft and hard. Key performance indicators (KPI) were:

Soft KPIs: Awareness, spontaneous and prompted; Consideration, including Axa on the consumers 'shopping list' (Source: IPSOS Brand Tracking monitored the entire test)

Hard KPIs: Number of quotes requested and number of policies sold (Source: Axa's Customer Insight Department)

Results were outstanding and by being able to measure the individual channels as a unit it followed that the integrated channels not previously used helped boost 'quotes' to 5 per cent higher than in the control area.
Before the test consideration was at 2 per cent in the test areas - the campaign increased this to 44 per cent. In the control areas consideration remained constant or fell.

Centralised data and communications planning allowed for call centre optimisation that, in turn, meant additional value not only in sales, but also in customer experience. This understanding and internal communication led to product optimisation for the cross-sell allowing for all sides of the business to win. By taking integration and applying it across the business, and by not simply adding media channels for the sake of it, AXA was able to grow its consideration among the public from a mere 2 per cent to 44 per cent.

\section{EXPERIENCE}

And now for perhaps the most elusive element of successful media integration: accessing the right talent.

Integrated media planning requires a 'rounded' understanding of the best combination of media to meet client objectives. If the consumer does not 'pigeon-hole' communications into the 


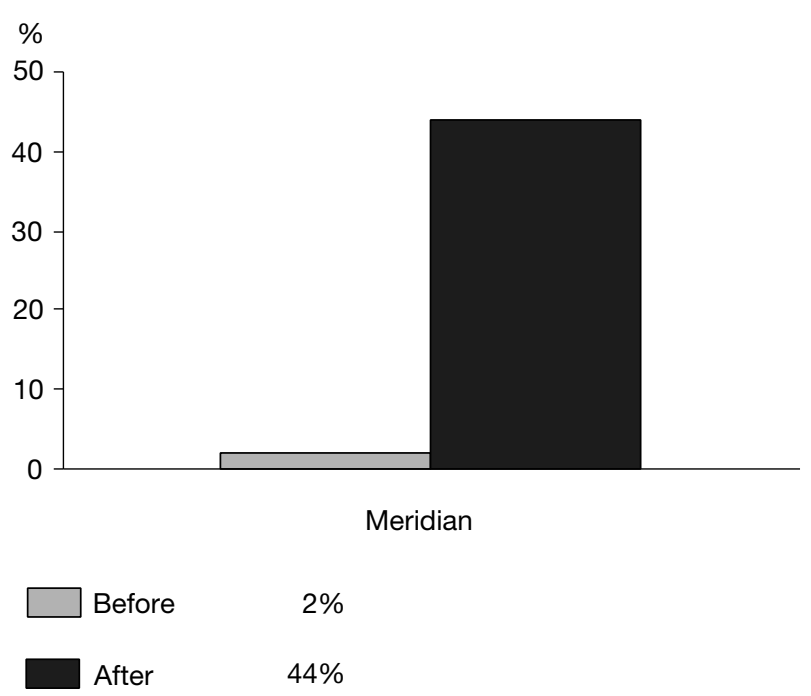

Figure 7 Motor consideration levels before and after 'hot housing' campaign

direct response or brand messaging 'boxes', then media planners should resist the mentality whereby the choice between 'direct' or 'brand' is seen as diametrically opposed.

It requires the integrated media planner to show ambidexterity, the knowledge of both brand and direct, and an acceptance that all media channels are capable of delivering to both disciplines, albeit to varying degrees. The art lies is knowing how and when to 'flex' the direct or branding capabilities of those selected channels in order to capture valuable customers and to meet campaign objectives.

The best solution is to take a more robust training approach for graduates; based on the view that creating media neutral planners 'from the ground up' is the way forward and that attempting to change the spots of a leopard can prove more hazardous. It is also helpful that several marketing industry organisations are grasping the nettle and running workshops to help create this new breed of media planner.

A thorough understanding of how each channel works and how it will work for the client is absolutely essential for integrated media planning. It has to work for the brand, the client and the customer. Clients, more than ever before, need to feel confident that their agency is planning with their best interest in mind and not just suggesting a strategy that is achievable within the confines of the agency's own ability parameters. The right experience is key to having a successful team in a service business.

\section{CONCLUSION}

Neutrality is a very passive term and does an injustice to the contextual effect of the medium that carries the message. For as long as television remains a socially cohesive medium; the magazine an aid to relaxation; the radio a signal of private space; the internet a window on an infinite world, the consumer cannot but be affected by the context in which messages and communications are carried. There can be no prospect of neutrality with personal tools such as the telephone, the e-mail and the letter box, where there is a risk of 
commercial overuse and consumer reaction against perceived invasion of their privacy.

Sustained, accountable and strategic media integration is the route to cohesive brand communication. All media planning should be driven by brand and consumer understanding and the selected channels should work together to convey the same message and values, no matter how the consumer prefers to orchestrate the process.

\section{References}

1 Future Foundation (2002) 'Network Society'.

2 Kit Kat case study based on a speech made by Andrew Harrison, Marketing Director for Nestlé Rowntree, at the RAB 2001 Advertiser Conference 'Harnessing the Power of Radio'.

3 AXA Case study for WWAV Media (2002). 